\title{
Consideration of Internal Governance Structure of New Rural Cooperative Organization in China
}

\author{
Li Liu \\ School of Marxism, Jilin Agricultural University, Changchun, Jilin 130018, China \\ Liuliu99666@126.com
}

\begin{abstract}
Keywords: new rural cooperative economic organizations, internal governance structure,
\end{abstract} suggestions.

\begin{abstract}
After the 30 years' reform until now, there are still several defects existing in Chinese most of new rural economic cooperative organizations like the low development degree and incomplete functions especially the apparent defects in the internal governance structure, which influence its development. Based on the internal governance structure of agricultural cooperative economic organization in China, it analyses the multi-models of agricultural cooperative economic organization and puts up the improvement countermeasures of new rural cooperative economic organizations from the aspect of system innovation.
\end{abstract}

\section{Introduction}

Chinese rural cooperative economic organizations was born in the 1940s and 1950s. Its prototype is junior and senior rural cooperative group. Nowadays, its development patterns and purposes are quite different from that in the birth of the cooperative economic organization. In the 1990s, with the economic globalization and the improvement of agricultural marketization, the contradiction between "small-scale farmers" and "great market" becomes increasing prominent. Rural cooperative economic organization is a special form of business organization under the circumstances of market economy, which improves the level of farmer organization, eliminate the abuses of farmer business diversification and plays an important role in association of "small-scale farmers" and "market". However in the rapid development process, because of the inherent shortage of Chinese rural economic organizations and nurture malnutrition, it lacks scientific management mechanisms, among them, the internal governance is one of the most prominent matters.

Specifically, affairs decision in rural economic organization should reflect farmers' wills, but most farmers cannot get good understanding on basic organizational management problems due to less educational quality. Therefore the truth is: the affairs decision right is on the hand of less people [1]. Secondly, minority control, the less participation and the virtual setting of internal supervision reduce the run performance of cooperation organization to a great extent.

Study on the internal governance structure of rural cooperative economy organization, figuring out the relationship between different structural characteristics of internal governance structure and the running performance in the cooperative organization are important theoretical and practical significance to improve cooperative governance and the performance of cooperatives.

\section{Internal Governance Modes of New Rural Cooperative Economic Organizations}

30 years' reform until now, the new development of rural economic cooperative organization has experienced twists and turns forming a variety of operational modes. In accordance with internal governance, it can be divided into three categories: Government Guide, Capable Governance and Corporate Governance [2].

\subsection{Government Guide}

As the builders and managers, government takes in charge of internal governance and external management, which fully reflects its model for government-led awareness and absolute control of 
rights. Organization manager is appointed by the government, such as village Party Secretary, so the supervisory board virtually exists. This kind of decision-making mechanism lacks flexibility and democracy, to a certain extent it cannot play function (as shown in Fig. 1). This type of organization management mode is the mainstream model in underdeveloped regions.

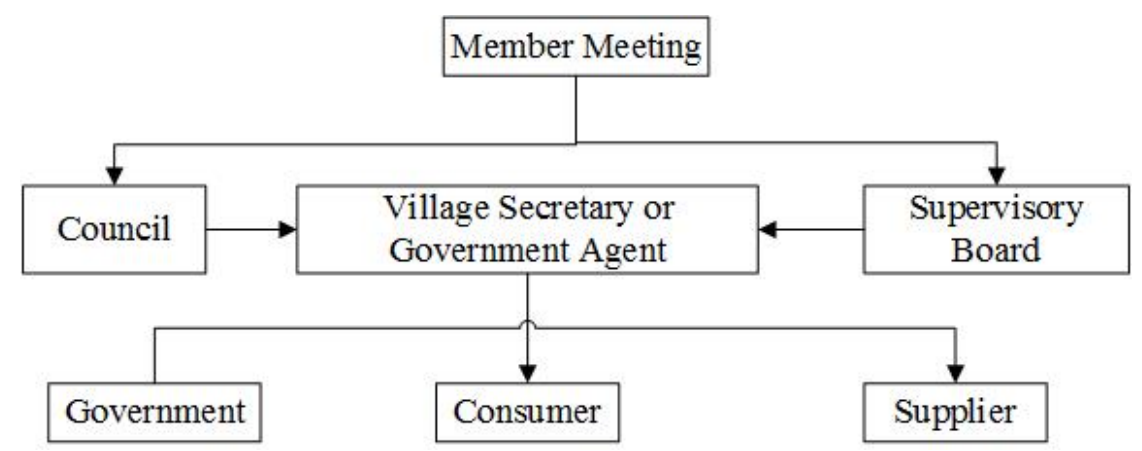

\subsection{Capable Guide}

Figure 1 Internal Governance Mode of Government Guide

In the rural areas with shortage of funds, technology and information resources, certain economic and technical capacity, relatively new rural people, major grower, large breeding and technical experts organize farmers to build spontaneously formed cooperative organization. But such kind of organizations always lack professional management experience, so their basic characteristics are as follows: the simple organizational structure, incomplete internal operation mechanism. So the organizational decisions are generally determined by capacity and its internal and external governance model is simple with weak communication skills and financial capacity (as shown in Fig. 2).

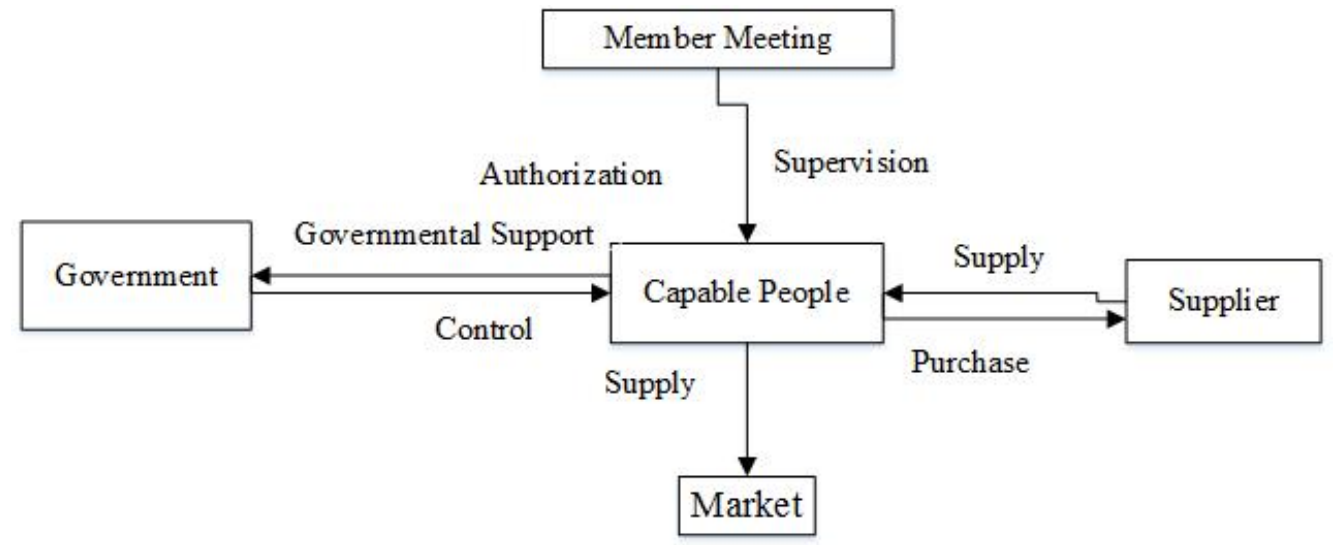

\subsection{Corporate Guide}

Figure 2 Internal Governance Mode of Capable Guide

Corporate guidance internal and external governance mode of operation mainly uses the company's resources and build internal governance mode based on stockholding system, the concrete structure is shown in Fig. 3. Compared with the previous two cooperative organization mechanisms, there are four differences:

(1)Cooperative organization managers are mainly appointed by corporate professional managers;

(2)Cooperative organization is generally operated as a corporate governance mode, especially in the planning, decision-making, organization, production, processing, sales, finance and other aspects to play an important function;

(3)Cooperative organization system is sound and the organizational structure is complete and the board of supervisors can fully exercise their right of supervision.

(4) On the decision-making mechanism, it operates according to the principle of organizationl operation to improve the government and market discourse to some extent. 


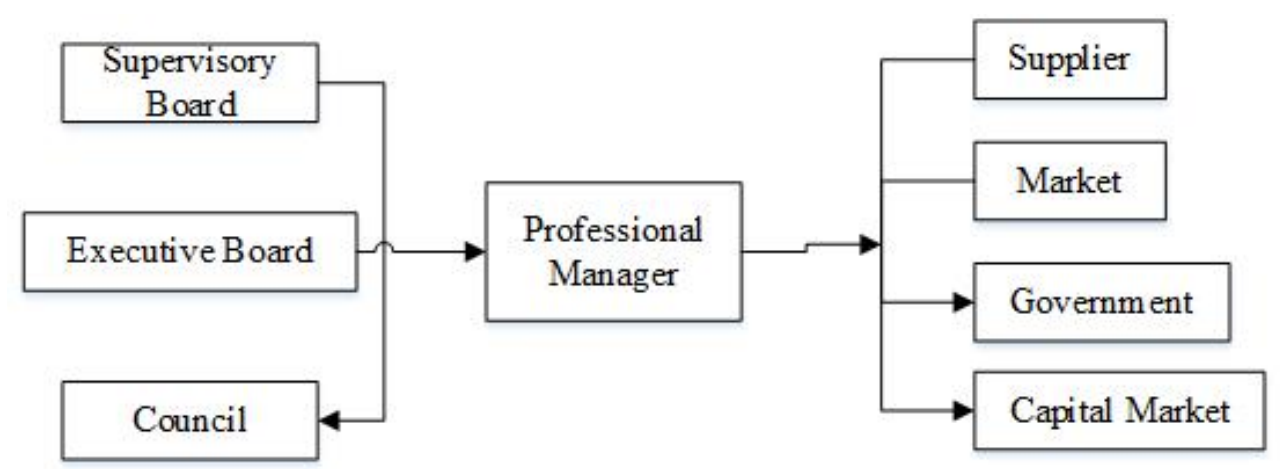

Figure 3 Internal Governance Mode of Corporate Guide

\section{Running Mode Defects Analysis of Rural Cooperative Economy Organization}

\subsection{Incomplete Property System}

From the perspective of property rights, most of currently existed cooperation economic organizations have confused property boundary which shows in the following aspects:

(1) Incomplete external legal person property rights. Due to the lack of specialized cooperatives, it causes the cooperative organization with no independent and clear legal person status. Currently it's about $70 \%$ of farmer cooperative organization registered in the department of agriculture, $20 \%$ in the civil affairs department registered as social group, $10 \%$ as enterprise legal person registered in the department of industry and commerce. The unclear legal person property rights take difficulties for production and business operation, nature determination and the choice of national support policy of cooperation organization;

(2)Vague internal property boundary. In the early period of establishment, the property boundary of cooperation is clear between individuals within the organization and between normal members and dependent investment subject due to the less input capital, less member. But with the increasing participants of members, the increase of the national support funds and the raise level of profit, the property border right becomes increasingly blurred, which often causes the erosion of national and individual benefits among investment subjects such as leading enterprises, supply and marketing cooperative, the rural talents [3].

\subsection{Negative Effect of "One man, one vote" principle of democratic decision-making}

(1)"One man, one vote" principle is a kind of democracy on surface, not in the sense of justice and efficiency democracy. The new rural economic cooperation organization is still in the primary stage of development. Both large and small families are organizational incentive to participate in the object. Sometimes it even mobilize large resources to drive the small to push the group scale reducing transaction costs and achieving scale economy. If only emphasize the rights average in the number of the democratic decision-making, it especially make bad decisions due to the superiority of small families number causing the transaction costs increase, the rights decreasing and the exit of large families and finally weakening the organization power.

(2)Low management efficiency among members. Cooperation organization's democratic management principles require that the significant management, investment allocation decisions must vote through member's congress. This decision-making mechanism and the internal governance pattern seemingly reflect and ensure the equality of the organization but on the objective side, it is at the cost of low efficiency, high cost and high risk. Membership requirements get superficial consideration but the decision-making process is slow with inadequate science even can't adapt to the change of the market effectively. Cooperation organization, therefore, whether to choose "democracy" or "efficiency" still worth exploring. 


\section{Countermeasures of Internal Governance of Rural Cooperative Economy Organization}

Based on the matters analysis above, the following suggestions have been put up.

\subsection{Property Right System Innovation}

Property rights system is the core of the economic system. Only establishing a clear and efficient property right system can ensure economic organization with health and sustainable development [4].At the beginning of the cooperation organization, it must use the way like capital stock issuing, capital account setting up to figure out the invested capital share of nation, member individual and leading corporates or other economic entities to prevent the collective and individual property rights confusion and the loss of organization of assets.

\subsection{Establishment of a "Multi Persons, One vote, One Person Multi votes" System}

The decision-making mechanism of "multi persons, one vote and one person multi votes" can embody the principle of equality and efficiency. "One person one vote" consideres the head of the right, ignoring the allocation of resources and ability. "Multi persons, one vote, one person multi votes" system takes into account the fairness and reflects the efficiency which is based on the size of the business, the number of shares, individual ability and other factors to allocate resources and determine the size of the voting rights. Several members whose right can not vote can vote together, namely "multi person, one vote". One person with great rights can get more votes, namely the limited "one person multi votes " and get to a maximum according to the actual decision. The system of "multi persons, one vote, one person multi votes" system solves the problem of "one person, one vote".

Anyway, constructing a true sense "democracy, fairness and efficiency" decision-making mechanism of new rural cooperative economic organizations is the key to internal organizational governance which will promote the organization incentive mechanism, supervision mechanism, profit distribution, relationship between members more optimized, more enthusiasm.

\section{Acknowledgements}

Humanities and Social Sciences project from Ministry of Education: Mechanism Innovation and operation mechanism cooperative economic organizations of Chinese farmers - in Jilin Province (12YJC790118); Social Science Fund Project of Jilin Province: Contemporary Value of Marx and Engels Thought on Cooperative Economy (Project No: 2015M7) series of results.

Liu Li, Associate Professor, School of Marxism, Jilin Agricultural University, he received his PhD in Jilin University, Master Instructor, research direction: Agricultural Economics and Management.

\section{References}

[1]. Yin Yanqiang. Cultivation and perfection the new rural economic organization [J]. Chinese Market. Vol. 818 (2015) No. 3, p. 18-19.

[2]. Tan Jing, Rao Kaiyu, Lei Junzhong. New rural economic cooperation organization innovation research based on "one person one vote" decision-making mechanism and innovation breakthrough [J]. Rural Economy, 2008, (11):127-129.

[3]. Hao Xiaobao. Profit mechanism and governance structure analysis of rural cooperative economy organization [J]. Journal of Socialist Theory Guide, 2009, (4).

[4]. Bi Jiamei. Governance Structure Thinking of Rural Cooperative Economy Organization [J]. Rural Economy Matters, 2009, (10). 